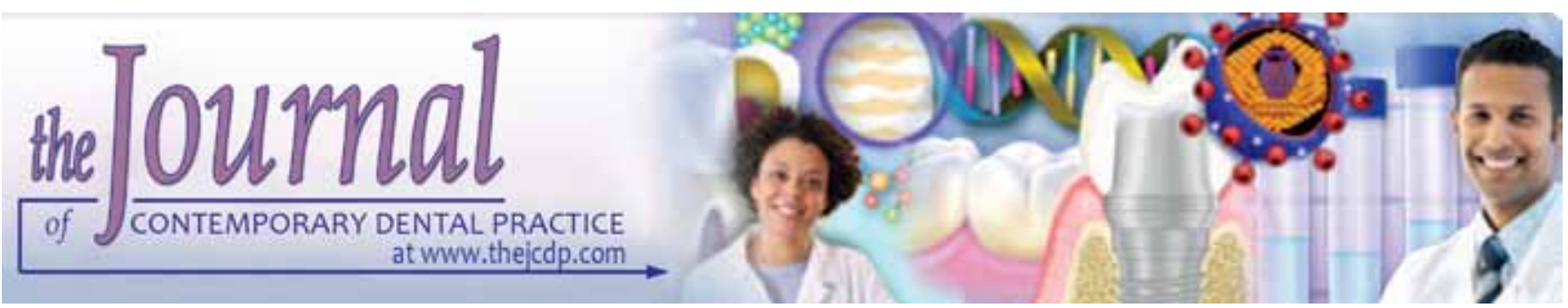

\title{
Effect of Collagen Matrix Saturation on the Surface Free Energy of Dentin using Different Agents
}

\author{
${ }^{1}$ Leopoldina de Fátima Dantas de Almeida, ${ }^{2}$ Samilly Evangelista Souza, ${ }^{3}$ Aline Araújo Sampaio \\ ${ }^{4}$ Yuri Wanderley Cavalcanti, ${ }^{5}$ Wander José da Silva, ${ }^{6}$ Altair A Del Bel Cur, ${ }^{7}$ Josimeri Hebling
}

\begin{abstract}
Introduction: The surface free energy of conditioned-dentin is one of the factors that interfere with monomeric infiltration of the interfibrillar spaces. Saturation of the tooth matrix with different substances may modulate this energy and, consequently, the wettability of the dentin.
\end{abstract}

Aim: To evaluate the influence of different substances used to saturate conditioned-dentin on surface free energy (SFE) of this substrate.

Materials and methods: Dentin blocks $(4 \times 7 \times 1 \mathrm{~mm}, \mathrm{n}=6$ / group), obtained from the roots of bovine incisors, were etched using phosphoric acid for 15 seconds, rinsed and gently dried. The surfaces were treated for 60 seconds with: ultra-purified water $\left(\mathrm{H}_{2} \mathrm{O}\right.$ - control); ethanol (EtOH), acetone (ACT), chlorhexidine ( $\mathrm{CHX}$ ), ethylenediaminetetraacetic acid (EDTA); or sodium hypochlorite $(\mathrm{NaOCl})$. The tooth surfaces were once again dried with absorbent paper and prepared for SFE evaluation using three standards: water, formamide and bromonaphthalene. Analysis of variance (ANOVA) and Dunnet's tests $(\alpha=0.05)$ were applied to the data.

Results: Ethylenediaminetetraacetic acid was the only substance that caused a change to the contact angle for the

\footnotetext{
${ }^{1}$ Department of Restorative Dentistry, Araraquara Dental School, University Estadual Paulista-UNESP, Araraquara São Paulo, Brazil

2,3,5,6 Department of Prosthodontics and Periodontology Piracicaba Dental School, University of Campinas, Piracicaba São Paulo, Brazil

${ }^{4}$ Department of Dentistry, State University of Paraiba (UEPB) Campina Grande, Paraiba, Brazil

${ }^{7}$ Department of Orthodontics and Pediatric Dentistry, Araraquara Dental School, University Estadual Paulista-UNESP Araraquara São Paulo, Brazil

Corresponding Author: Josimeri Hebling, Professor Department of Orthodontics and Pediatric Dentistry, Araraquara Dental School,University Estadual Paulista-UNESP, Araraquara Humaitá, 1680, São Paulo, Brazil, Phone: (+55) 16-3301-6334 e-mail: jhebling@foar.unesp.br
}

standards water and formamide, while only EtOH influenced the angles formed between formamide and the dentin surface. None of the substances exerted a significant effect for bromonaphthalene. In comparison to the control, only EDTA and $\mathrm{NaOCl}$ altered both polar components of the SFE. Total SFE was increased by saturation of the collagen matrix by EDTA and reduced when $\mathrm{NaOCl}$ was used.

Conclusion: Saturation of the collagen matrix by EDTA and EtOH changed the surface free energy of the dentin. In addition, the use of $\mathrm{NaOCl}$ negatively interfered with the properties evaluated.

Clinical significance: The increase of surface free energy and wettability of the dentin surface would allow higher penetration of the the adhesive system, which would be of importance to the clinical success of resin-dentin union.

Keywords: Dentin, Surface properties, Tooth acid-etching, Surface free energy.

How to cite this article: de Almeida LFD, Souza SE, Sampaio AA, Cavalcanti YW, da Silva WJ, Cur AADB, Hebling J. Effect of Collagen Matrix Saturation on the Surface Free Energy of Dentin using Different Agents. J Contemp Dent Pract 2015;16(7):531-536.

Source of support: Nil

Conflict of interest: None

\section{INTRODUCTION}

Acid-etching of the tooth surface leads to exposure of the collagen fibrils due to removal of mineral content from the tissues. ${ }^{1}$ After acid etching, and correct washing of the substrate, these fibrils should be completely encapsulated by monomers derived from adhesive systems. Following polymerization of these monomers, the formation of a hybrid layer is observed, which is considered the principal structure for retention and sealing of the tooth submitted to adhesive restorative treatments. ${ }^{2}$

However, encapsulation of the collagen fibrils by resin monomers is incomplete, allowing them to remain 
exposed. ${ }^{1}$ This limitation results in failure of the hybrid layer and leads to its degradation over time, particularly in the presence of water. ${ }^{2-4}$ Therefore, the hybrid layer has also been considered the most fragile part of the resindentin union. ${ }^{5}$ Longitudinal stability of this adhesive interface is guided by the structural characteristics and composition of the tooth substrate, as well as the physicochemical features of the adhesive system. ${ }^{2}$

Factors that directly affect the hybrid layer includewettability, removal of the smear layer and composition of the adhesive system. ${ }^{6}$ In addition, the runoff and diffusion of the adhesive system between the interfibrillar spaces may be influenced by the surface free energy (SFE) of the dentin. ${ }^{78}$

The SFE, represented by ' $\gamma$ ', is a physical property defined by the sum of polar and non-polar force components on solid surfaces. ${ }^{9}$ These forces encompass the presence of London interactions between the non-polar molecules, non-dispersive forces represented by metallic and electrical interactions and by hydrogen bonds that represent polar interactions; principally with water molecules and hydroxyl components. ${ }^{10}$ The SFE is, therefore, directly proportional to the hydrophilic or hydrophobic characteristics of the substrate, which can be measured using the contact angle between the solid surface and wetting agent. ${ }^{7}$ Therefore, the wettability of the surface that receives the adhesive system must be indicated by the contact angle. ${ }^{7,11}$

Treatment to the tooth surface may affect its free surface energy. In addition, the presence of the smear layer may reduce and complicate wetting of the tooth surface, while its removal results in the opposite. ${ }^{12}$ However, the action of acid-conditioning on SFE of the dentin, in terms of removal of the smear layer, remains controversial. While removal of the mineral content with exposure of the organic content has been observed to reduce the SFE, having a negative impact on its wettability, ${ }^{13}$ the opposite result has also been demonstrated. ${ }^{7}$

Various substances have been used as saturation agents for previously etched dentin, for application of the adhesive system. The aim of this search was to better understand the monomeric infiltration of the tooth matrix, particularly with dimethacrylate monomers, such as bisphenylglycidyl dimethacrylate, urethane dimethacrylate and triethylene glycol dimethacrylate. Due to their hydrophobic properties, these monomers form polymers that are resistant to hydrolytic degradation, significantly reducing the decomposition of the hybrid layer during the functionality of the adhesive bond. ${ }^{14}$ Ethanol, for example, has been demonstrated to allow the water content present in the interfibrillar spaces to be removed, facilitating the infiltration of these dimethacrylates. ${ }^{14-16}$
Chlorhexidine, in turn, has been used as a nonspecific inhibitor of tooth metalloproteinase activity, resulting in a deceleration in degradation of the hybrid layer and, consequently, improving the longevity of the resin-dentin bond. ${ }^{17-19}$ However, chlorhexidine has been shown, even in its alcohol carrier, not to improve the wettability of dentin conditioned by the single bond 2 adhesive system. ${ }^{12}$

Since, the effects of different substances on the SFE of dentin are not well known, and its physical properties directly affect the wettability of this tissue, the aim of this study was to evaluate the influence of the saturation of dentin conditioned with ethanol, acetone, chlorhexidine, EDTA and sodium hypochlorite; on the SFE of this substrate. The null hypothesis was that the treatments did not significantly influence the SFE of dentin conditioned with phosphoric acid.

\section{MATERIALS AND METHODS}

\section{Experimental Design}

A blind in vitro study was performed, with random allocation of the samples and data analysis. The independent study variable was the treatment used on preconditioned (37\% phosphoric acid) tooth surface, while the dependent variables were the SFE and the conditioned dentin surface morphology.

\section{Sample Preparation}

Dentin samples ( $n=6$ /group) were obtained from bovine incisor roots, with two blocks per root and stored in $2 \%$ formaldehyde solution. The blocks were initially cut into $4 \times 7 \mathrm{~mm}$ and then worn on both faces of the block until reaching a thickness of $1 \mathrm{~mm}$. Uniformity of the surfaces was achieved via planning with aluminum oxide files (grains 400, 600 and 1,200) and polishing (Phoenix Beta, Buehler, Lake Bluf, IL, USA) under running water for 4 minutes.

\section{Tooth Treatments-Saturation Solutions for the Conditioned Dentin}

The samples were etched with $37 \%$ phosphoric acid (Ultradent, Salt Lake City, USA) for 15 seconds and rinsed with ultrapurified water for a further 15 seconds. The dentin surface was then carefully dried with absorbent paper and submitted to one of the following treatmentsultra-purified water $\left(\mathrm{H}_{2} \mathrm{O}\right.$ - Control, Sigma Aldrich, St Louis, USA), 99\% ethanol (EtOH, Sigma Aldrich, St Louis, USA), 99\% acetone (ACT, Sigma Aldrich, St Louis, USA), $2 \%$ chlorhexidine (CHX, DFL, Rio de Janeiro, Brazil), 17\% ethylenediaminetetraacetic acid (EDTA, Biodinâmica, Ibiporã, Brazil) or $0.5 \%$ sodium hypochlorite $(\mathrm{NaOCl}$, 
Biodinâmica, Ibiporã, Brazil). Each substance was inserted onto pretreated disks using a volume of $200 \mu \mathrm{l}$, with a contact time of 60 seconds. The specimens were then dried again with absorbent paper and submitted to SFE evaluation.

\section{Evaluation of Surface Free Energy}

Surface free energy (SFE) $\left(\gamma^{\mathrm{s}}\right)$ was evaluated by a goniometer (Ramé-Hart 500; Ramé-Hart Instrument Co, Succasunna, NJ, USA) using three solutions: ultrapure water, 99.5\% formamide (Sigma-Aldrich Corp, St Louis, MO, USA) and 99\% bromonaphthalene (Sigma-Aldrich Corp, St Louis, MO, USA); as described by Combe. ${ }^{20}$

The contact angle formed between the tooth surface $(n=6)$ and the sessile droplet of the solutions described $(10 \mu \mathrm{l})$ was measured, and the values used to calculate the SFE. ${ }^{20}$ The measurements were performed in triplicates at room temperature. The contact angle, polar and dispersive components and the total SFE were calculated using the software attached to the instrument (DROPImage Software, Ramé-Hart Instrument Co, Succasunna, NJ, USA).

\section{STATISTICAL ANALYSIS}

The data were analyzed in terms of their distribution (Kolmogorov-Smirnov test) and homoscedasticity (Levene F-test). Once reaching the criteria of normal distribution and homoscedasticity, the data were submitted to the oneway analysis of variance test (substances), with post hoc Dunnet test, using the SigmaPlot 11 software (SigmaPlot v 11, Systat Software Inc, San Jose, USA). The significance level adopted was 5\%.

\section{RESULTS}

The contact angles obtained for the different substances used to determine SFE have been presented in Table 1. A significant difference was observed between the substances only for the contact angles obtained with water and formamide. Saturation of the dentin conditioned with EDTA resulted in smaller contact angles as compared to control (ultrapure water) when water and formamide
Table 1: Contact angles according to substances used for surface free energy measurement

\begin{tabular}{llll}
\hline & \multicolumn{3}{c}{ Contact angles $(\theta)$} \\
\cline { 2 - 4 } Treatments & Water & Formamide & Bromonaphthalene \\
\hline $\mathrm{H}_{2} \mathrm{O}$ & $69.52 \pm 2.83^{\mathrm{A}}$ & $53.41 \pm 7.30^{\mathrm{A}}$ & $46.39 \pm 3.79^{\mathrm{A}}$ \\
(control) & & & \\
$\mathrm{EtOH}$ & $65.66 \pm 5.51^{\mathrm{AB}}$ & $47.97 \pm 3.29^{\mathrm{B}}$ & $46.45 \pm 7.37^{\mathrm{A}}$ \\
$\mathrm{ACT}$ & $73.38 \pm 6.54^{\mathrm{A}}$ & $56.22 \pm 6.24^{\mathrm{A}}$ & $44.39 \pm 5.37^{\mathrm{A}}$ \\
$\mathrm{CHX}$ & $71.69 \pm 5.76^{\mathrm{A}}$ & $53.38 \pm 5.37^{\mathrm{A}}$ & $43.52 \pm 6.75^{\mathrm{A}}$ \\
$\mathrm{EDTA}$ & $63.94 \pm 4.11^{\mathrm{B}}$ & $46.14 \pm 3.55^{\mathrm{B}}$ & $47.32 \pm 3.57^{\mathrm{A}}$ \\
$\mathrm{NaOCl}$ & $71.39 \pm 3.89^{\mathrm{A}}$ & $61.30 \pm 5.13^{\mathrm{A}}$ & $45.67 \pm 5.36^{\mathrm{A}}$ \\
\hline
\end{tabular}

Numbers are mean \pm standard deviation $(n=6)$; Different uppercase letters in superscript in the same column show statistical significant differences $(p<0.05)$ between any two groups

were used, while the same effect was shown for saturation with $\mathrm{EtOH}$ for formamide only.

The SFE of the tooth substrates after the different treatments evaluated has been shown in Table 2. The groups treated with EDTA and ethanol presented higher SFE values, although the last one did not differ from the control. On the other hand, lower SFE values were seen following saturation of the dentin conditioned with $\mathrm{NaOCl}$. Neither the ACT nor the CHX exerted an effect on SFE as compared to the control.

Sodium hypochlorite was the only substance that modified SFE components. When saturated with $\mathrm{NaOCl}$, the conditioned dentin presented polar properties, with a decrease in positive polarity [polar $(+)$ ] and an increase in negative polarity [polar (-)] (Table 2$)$. The lack of a significant difference between the remaining groups indicates a predominantly hydrophilic surface behavior.

\section{DISCUSSION}

The hypothesis tested in the present study was partially rejected since some of the substances evaluated significantly altered the SFE. Only the groups treated with EtOH and EDTA influenced the contact angles, while the latter and $\mathrm{NaOCl}$ exerted a significant effect over the total SFE. These results suggest that these substances could affect the infiltration of dentin conditioned by adhesive systems.

The runoff capacity of a liquid over a surface, also known as wettability, is directly associated with the SFE of such surface. ${ }^{21}$ Therefore, greater the surface energy,

Table 2: Surface free energy components of dentin slabs after saturation of the etched dentin with different solutions

\begin{tabular}{llllll}
\hline Dentin treatments & Polar component & Polar $(+)$ & Polar $(-)$ & Dispersive component & Total surface energy mN/m \\
\hline $\mathrm{H}_{2} \mathrm{O}$ (control) & $10.35 \pm 2.04^{\mathrm{A}}$ & $2.53 \pm 0.93^{\mathrm{A}}$ & $14.58 \pm 2.68^{\mathrm{A}}$ & $25.75 \pm 2.74^{\mathrm{A}}$ & $36.15 \pm 0.66^{\mathrm{A}}$ \\
$\mathrm{EtOH}$ & $10.48 \pm 1.97^{\mathrm{A}}$ & $3.03 \pm 0.74^{\mathrm{A}}$ & $12.45 \pm 4.27^{\mathrm{A}}$ & $27.53 \pm 1.26^{\mathrm{A}}$ & $38.03 \pm 1.09^{\mathrm{AB}}$ \\
$\mathrm{ACT}$ & $8.20 \pm 2.01^{\mathrm{A}}$ & $1.47 \pm 0.40^{\mathrm{B}}$ & $10.85 \pm 2.44^{\mathrm{A}}$ & $27.85 \pm 1.15^{\mathrm{A}}$ & $35.28 \pm 1.04^{\mathrm{A}}$ \\
$\mathrm{CHX}$ & $9.15 \pm 4.44^{\mathrm{A}}$ & $1.38 \pm 0.66^{\mathrm{B}}$ & $10.65 \pm 3.68^{\mathrm{A}}$ & $27.03 \pm 3.41^{\mathrm{A}}$ & $36.15 \pm 1.19^{\mathrm{A}}$ \\
$\mathrm{EDTA}$ & $14.13 \pm 3.38^{\mathrm{A}}$ & $3.20 \pm 1.42^{\mathrm{A}}$ & $15.38 \pm 2.03^{\mathrm{A}}$ & $25.93 \pm 2.76^{\mathrm{A}}$ & $40.03 \pm 1.36^{\mathrm{B}}$ \\
$\mathrm{NaOCl}$ & $4.03 \pm 2.30^{\mathrm{B}}$ & $1.67 \pm 0.26^{\mathrm{B}}$ & $20.00 \pm 2.31^{\mathrm{B}}$ & $26.28 \pm 1.87^{\mathrm{A}}$ & $30.30 \pm 0.74^{\mathrm{C}}$ \\
\hline
\end{tabular}

Numbers are mean \pm standard deviation $(n=6)$; Different uppercase letters in superscript in the same column show statistical significant differences $(p<0.05)$ between any two groups 
greater is its wettability, demonstrated by the formation of smaller contact angles. The same positive correlation between these variables was observed in the present study also. In turn, SFE is influenced by the composition of the substrate, where the resultant forces are obtained due to molecular interactions. ${ }^{8}$ In this study, saturation of the dentin conditioned with EDTA or $\mathrm{NaOCl}$ was observed to modify the behavior of the substrate in relation to the control $\left(\mathrm{H}_{2} \mathrm{O}\right)$.

Ethylenediaminetetraacetic acid promoted an increased SFE, as well as an affinity for polar substances, for instance for water and formamide (smaller contact angles, Table 1). Formamide is an amine derived from formic acid in a clear liquid form, which is miscible in water. ${ }^{22}$ Therefore, EDTA and formamide, which presented surface tensions of 72.9 and 58.4 dynes/cm respectively, are considered polar substances. ${ }^{22}$ 2-hydroxyethyl methacrylate (HEMA), which presents a hydrophilic grouping within its molecule, is recognized as the main monomer present in tooth adhesives. Therefore, it is reasonable to suggest that an increased SFE and affinity for polar substrates induced by saturation of dentin conditioned with EDTA, would potentiate the infiltration of the collagen matrix with HEMA.

The ethanol-wet bond technique, first demonstrated by Pashley, ${ }^{14}$ aims to substitute the water present in the interfibrillar spaces of the dentin exposed to ethanol, temporarily transforming the hydrophilic environment of the conditioned dentin into a hydrophobic one. This procedure allows the resin monomer to impregnate the collagen fibrils. ${ }^{23}$ However, the results of the present study do not support the assumption that the use of $\mathrm{EtOH}$ exerts an effect on the SFE of conditioned dentin. This may also be concluded by the fact that $\mathrm{EtOH}$ does not change the contact angles formed by bromonaphthalene (surface tension of 38.9 dynes $/ \mathrm{cm}$ ). This substance is an oily liquid with low solubility in water. Likewise, dimethacrylates do not present an affinity for water due to being highly hydrophobic.

Hydrophobic adhesive systems possess more stable chemical and mechanical properties. ${ }^{24,25}$ However, the interaction of these systems with wet dentin can be impaired. Regarding the results of the present study, saturation of dentin conditioned with ethanol (ethanolwet bonding) was observed to improve the wettability and runoff of the adhesive systems, ${ }^{26}$ in addition to increased impregnation of the hydrophobic monomers. ${ }^{14}$

Ethylenediaminetetraacetic acid solution as well as removing the smear layer, is considered a calcium-chelating agent. ${ }^{27}$ Therefore, modification of the dentin surface due to removal of these ions derived from hydroxyapatite, justifies the increase in SFE and the hydrophilic behavior of the substrates treated with EDTA. ${ }^{28}$ This increase in polarity may be caused by the decreased contact angles, providing a greater surface wettability by the polar substances. However, it is worth highlighting that the surface had already been previously etched, therefore having a greater loss of minerals and a larger number of exposed fibrils. While using EDTA in a clinical situation, one must consider that a resin monomer may not encapsulate all of the exposed collagen following conditioning and treatment of the surface, which may lead to failures at the adhesive interface.

On the other hand, saturation with $\mathrm{NaOCl}$ contributed to a decreased SFE and a greater affinity to non-polar substances. This treatment is capable of changing the tooth surface via destruction of the collagen matrix present at the surface, compromising the formation of the hybrid layer. ${ }^{29,30}$ Although, with water the contact angles did not reduce as observed by Aguilera, ${ }^{8}$ treatment with $\mathrm{NaOCl}$ significantly decreased the SFE values of the tooth substrate, which may have negatively interfered with monomeric infiltration. The deleterious effect on tooth adhesion exerted by this agent, which is vastly used for irrigation in endodontic treatment, has been shown to reduce bond strength. ${ }^{31}$

The use of chlorhexidine as a tooth treatment aimed to inhibit the action of enzymes, such as metalloproteinases and cathepsins, released following acid-conditioning. ${ }^{17,19}$ In the present study, saturation of dentin conditioned with CHX did not exert any effects over the SFE. Similar results were described by Ricci, $^{19}$ even when using chlorhexidine with alcohol as its carrier. However, due to its beneficial effects in decelerating degradation of the hybrid layer ${ }^{17,19,26}$ as well as its neutrality in relation to infiltration of dentin by resin monomers, $\mathrm{CHX}$ remains the treatment indicated following acid-etching.

The results of the present study allow one to assume that treatment of a tooth substrate previously conditioned with EDTA and $\mathrm{NaOCl}$ may interfere with the reactivity of the surface, influencing the behavior of the dentin in contact with adhesive systems. Therefore, further studies must be performed to investigate the effects of these surface treatments while using these systems. One should highlight that differences exist between sound substrates and those affected by carious lesions, ${ }^{32}$ which may interfere with the SFE and contact angle. ${ }^{12}$ In addition, one should take into account both the heterogeneity and the roughness of the tooth tissues. ${ }^{32}$

\section{CONCLUSION}

Of the substances evaluated, SFE was observed to be altered by exposure to EDTA, which corroborated the use of this adhesive technique, while the same was not 
demonstrated with the use of ethanol. In addition, despite changing the SFE, treatment with $\mathrm{NaOCl}$ is not indicated due to degradation of the collagen matrix.

\section{CLINICAL SIGNIFICANCE}

The results suggest that $\mathrm{NaOCl}, \mathrm{EtOH}$ and EDTA affect the SFE of dentin, which could interfere with infiltration of adhesive systems within the preconditioned dentin. This would be of significance to the success of dental restorations.

\section{REFERENCES}

1. Grégoire G, Guignes P, Nasr K. Effects of dentine moisture on the permeability of total-etch and one-step self-etch adhesives. J Dent 2009;37(9):691-699.

2. Hashimoto M. A review-micromorphological evidence of degradation in resin-dentin bonds and potential preventional solutions. J Biomed Mater Res B Appl Biomater 2010;92(1): 268-280.

3. Tjaderhane L, Nascimento FD, Breschi L, Mazzoni A, Tersariol IL, Geraldeli S, Tezvergil-Mutluay A, Carrilho M, Carvalho RM, Tay FR, et al. Strategies to prevent hydrolytic degradation of the hybrid layer: a review. Dent Mater 2013;29(10):999-1011.

4. Culbertson BM. New polymeric materials for use in glassinomer cements. J Dent 2006;34(8):556-565.

5. Spencer P, Ye Q, Park J, Topp EM, Misra A, Marangos O, Wang Y, Bohaty BS, Singh V, Sene F, et al. Adhesive/dentin interface: the weak link in the composite restoration. Ann Biomed Eng 2010;38(6):1989-2003.

6. Van Landuyt KL, Snauwaert J, De Munck J, Peumans M, Yoshida Y, Poitevin A, Coutinho E, Suzuki K, Lambrechts P, Van Meerbeek B. Systematic review of the chemical composition of contemporary dental adhesives. Biomaterials 2007;28 (26):3757-3785.

7. Aguilar-Mendoza JA, Rosales-Leal JI, Rodríguez-ValverdeMA, González-López S, Cabrerizo-Vílchez MA. Wettability and bonding of self-etching dental adhesives. Influence of the smear layer. Dent Mater 2008;24(7):994-1000.

8. Aguilera FS, Osorio R, Osorio E, Moura P, Toledano M. Wetting ability of an acetone/based etch and rinse adhesive after NaOCl-treatment. Med Oral Patol Oral Cir Bucal 2012; 17(4):644-648.

9. Hata T, Kitazaki Y, Saito T. Estimation of the surface energy of polymer solids. J Adhesion 1987;21(3-4):177-194.

10. Comyn J. Contact angles and adhesive bonding. Int J Adhes Adhesives 1992;12(3):145-149.

11. Inoue N, Tsujimoto A, Takimoto M, Ootsuka E, Endo H, Takamizawa T, Miyazaki M.Surface free-energy measurements as indicators of the bonding characteristics of single-step selfetching adhesives. Eur J Oral Sci 2010;118(5):525-530.

12. Ricci HA, Scheffel DL, de Souza Costa CA, dos Santos FJ, Jafelicci M Jr, Hebling J. Wettability of chlorhexidine treated non-carious and caries-affected dentine. Aust Dent J 2014;59(1):37-42.

13. Farge $\mathrm{P}$, Alderete L, Ramos SM. Dentin wetting by three adhesive systems: influence of etching time, temperature and relative humidity. J Dent 2010;38(9):698-706.
14. Pashley DH, Tay FR, Carvalho RM, Rueggeberg FA, Agee KA, Carrilho M, Donnelly A, García-Godoy F. From dry bonding to water-wet bonding to ethanol-wet bonding: a review of the interactions between dentin matrix and solvated resins using a macromodel of the hybrid layer. Am J Dent 2007;20(1): 7-20.

15. Cadenaro M, Breschi L, Rueggeberg FA, Agee K, Di Lenarda R, Carrilho M, Tay FR, Pashley DH. Effect of adhesive hydrophilicity and curing time on the permeability of resins bonded to water vs ethanol-saturated acid-etched dentin. Dental Mater 2009;25(1):39-47.

16. Huang X, Li L, Huang C, Du X. Effect of ethanol-wet bonding with hydrophobic adhesive on caries-affected dentine. Eur J Oral Sci 2011;119(4):310-315.

17. Hebling J, Pashley DH, Tjaderhane L, Tay FR. Chlorhexidine arrests subclinical degradation of dentin hybrid layers in vivo. J Dent Res 2005;84(8):741-746.

18. Shimada Y, Ichinose S, Sadr A, Burrow MF, Tagami J. Localization of matrix metalloproteinases (MMPs-2, 8,9 and 20) in normal and carious dentine. Aust Dent J 2009;54(4): 347-354.

19. Ricci HA, Sanabe ME, de Souza Costa CA, Pashley DH, Hebling J. Chlorhexidine increases the longevity of in vivo resin-dentin bonds. Euro J Oral Sci 2010;118(4):411-416.

20. Combe EC, Owen BA, Hodges JS. A protocol for determining the surface free energy of dental materials. Dent Mater 2004; 20(3):262-268.

21. Attal JP, Asmussen E, Degrange M. Effects of surface treatment on the free surface energy of dentin. Dent Mater 1994;10(4):259-264.

22. Valdes TI, Ciridon W, Ratner BD, Bryers JD. Surface modification of a perfluorinated ionomer using a glow discharge deposition method to control protein adsorption. Biomaterials 2008;29(10):1356-1366.

23. Ekambaram M, Yiu CK, Matinlinna JP, Chang JW, Tay FR, King NM. Effect of chlorhexidine and ethanol-wet bonding with a hydrophobic adhesive to intraradicular dentine. J Dent 2014;42(7):872-882.

24. Sadek FT, Pashley DH, Nishitani Y, Carrilho MR, Donnelly A, Ferrari M, Tay FR. Application of hydrophobic resin adhesives to acid-etched dentin with an alternative wet bonding technique. J Biomed Mater Res A 2008;84(1): 19-29.

25. de Andrade e Silva SM, Carrilho MR, Marquezini Junior L, Garcia FC, Manso AP, Alves MC, de Carvalho RM. Effect of an additional hydrophilic versus hydrophobic coat on the quality of dentinal sealing provided by two-step etch-andrinse adhesives. J Appl Oral Sci 2009;17(3):184-189.

26. Manso AP,GrandeRH,Bedran-Russo AK, Reis A,LoguercioAD, Pashley DH, Carvalho RM. Can 1\% chlorhexidine diacetate and ethanol stabilize resin-dentin bonds? Dent Mater 2014;30(7):735-741.

27. Cecchin D, Farina AP, Galafassi D, Barbizam JV, Corona SA, Carlini-Júnior B. Influence of sodium hypochlorite and edta on the microtensile bond strength of a self-etching adhesive system. J Appl Oral Sci 2010;18(4):385-389.

28. Doğan H, Qalt S. Effects of chelating agents and sodium hypochlorite on mineral content of root dentin. J Endod 2001; 27(9):578-580. 
29. Mountouris G, Silikas N, Eliades G. Effect of sodium hypochlorite treatment on the molecular composition and morphology of human coronal dentin. J Adhes Dent 2004;6(3):175-182.

30. Correr GM, Alonso RC, Grando MF, Borges AF, PuppinRontani RM. Effect of sodium hypochlorite on primary dentin—a scanning electron microscopy (SEM) evaluation. J Dent 2006;34(7):454-459.
31. Fawzi EM, Elkassas DW, Ghoneim AG. Bonding strategires to pulp chambre dentin treated with diferente endodontics irrigants: microshear bond strength testing and SEM analysis. J Adhes Dent 2010;12(1):63-70.

32. Xuan W, Hou BX, Lü YL. Bond strength of different adhesives to normal and caries-affected dentins. Chin Med J (Engl) 2010;123(3):332-336. 